\title{
A review of Pharmacological Agents Used to Treat COVID-19 During the
}

\author{
Pandemic
}

\section{Covid 19 Pandemisi Sırasında Kullanılan Farmakolojik Ajanların Gözden Geçirilmesi}

\author{
Fikriye Yasemin ÖZATIK ${ }^{1}$
}

\section{$\underline{\ddot{O Z}}$}

2019 Aralık ayından itibaren Çin'de bir dizi pnomöni vakası bildirildi. Dünya Sağlı örgütü yapılan bir dizi araştırmadan sonra 11 Şubat 2020 de 2019- nCoV'un neden olduğu bu hastalığı koronavirüs hastalığı (COVID-19) olarak adlandırdı. COVID-19 küresel bir salgındır. Bu derlemede COVID-19 pandemisinde kullanılan ilaçların farmakokinetik ve farmakodinamik olarak değerlendirilmesi amaçlanmıştır.

COVID-19 pandemisinde kullanılan ilaçlar ile ilgili kanıtlar henüz kesin değildir. Bu ilaçlar ile ilgili daha çok çalışmaya ve daha çok bilgiye ihtiyaç duyulmaktadır.

Anahtar Kelimeler: COVID-19; ilaç; farmakodinamik; farmakokinetik

\section{ABSTRACT}

A number of pneumonia cases have been reported in China since December 2019. After a series of researches, the World Health Organization named this disease caused by $2019-\mathrm{nCoV}$ on 11 February 2020 as coronavirus disease (COVID-19). COVID-19 is a global pandemic. The aim of this review was to evaluate the pharmacokinetics and pharmacodynamics of the drugs used in COVID19 pandemic

Evidence for eficacy of the drugs used in the COVID-19 pandemic is not yet clear. Further studies and information are needed on these drugs.

Key Words: COVID-19; drug, pharmacodynamics; pharmacokinetics

Received: 05.10.2020; Accepted:03.01.2021

${ }^{1}$ Kutahya Health Sciences University, Faculty of Medicine, Department of Pharmacology. Kutahya, Turkey.

Corresponding Author: Assoc. Prof. Dr. Fikriye Yasemin ÖZATIK, Kutahya Health Sciences University, Faculty of Medicine, Department of Pharmacology. Kutahya, Turkey. e-mail: fyozatik@ hotmail.com 


\section{INTRODUCTION}

In December 2019, a group of patients were identified to have pneumonia with unknown cause in Wuhan city, State of Hubei in China. Interestingly, all the patients had visited the Huanan Seafood Wholesale Market and shopped there. In December, Chinese Disease Control and Prevention Center and Wuhan city health authorities reported a novel pneumonia epidemic. The Chinese Disease Control and Prevention Center researched samples taken from the respiratory tracts of patients and identified a novel coronavirus. This coronavirus was later named as "Severe acute respiratory syndrome coronavirus-2". The World Health Organization (WHO) named this virus as coronavirus disease-2019 (COVID-19) as it emerged in 2019. Later, this virus spread throughout China and was identified in 114 countries in the next three months and caused more than 4000 deaths. ${ }^{1}$ It still continues to spread. Currently, the mortality rate is rapidly rising worldwide. COVID-19 caused great fear all over the world. Almost every country in the world has begun taking emergency measures. ${ }^{2}$ COVID-19 is a highly contagious disease with a rather poor prognosis and can lead to many deaths.

There are some medications used in the treatment of COVID-19. However, the COVID-19 pandemic is spreading rapidly and clinical trials of drugs that affect this virus and its symptoms are still ongoing. It is crucial for clinical research to recognize the pharmacokinetic and pharmacodynamics of drugs frequently used in the COVID-19 pandemic. This review aims to assess the COVID-19 treatment choices in terms of pharmacodynamics and pharmacokinetics.

\section{MATERIALS and METHOD}

Articles written only in English related to COVID-19 treatment protocols up to 1 June 2020 were screened and investigated on PubMed. Our key words were COVID19, coronavirus, chloroquine, hydroxychloroquine, remdesivir, favipiravir, lopinavir, ritonavir, oseltamivir, nitazoxanide, nelfinavir, tocilizumab, plasma, immunoglobulins, corticosteroids, and azithromycin. Below the pharmacological activity and published clinical and preclinical experiences related to some medications researched for COVID-19 are reviewed.

\section{RESULTS}

\section{Some Medications Used For Coronavirus}

\section{Chloroquine-Hydroxychloroquine}

Chloroquine and hydroxychloroquine are used as antimalarial medication in addition to being used against a range of RNA viruses including Zika virus, Chikungunya virus, SARS-CoV and MERS. They are aminoquinoline class medications with proven efficacy against these viruses. ${ }^{3}$ The most accepted mechanism for chloroquine is inhibition of $\beta$ hematin formation in the digestive vacuoles of the malaria parasite. Additionally, the effect mechanisms of chloroquine are still debated. It is thought that effects are due to changing the digestive food vacuole $\mathrm{pH}$ and inhibition of lactate dehydrogenase. ${ }^{4}$ The in vitro effects of chloroquine were identified at the end of the 1960s. ${ }^{5}$ The growth of many different viruses in cell cultures is inhibited by both chloroquine and hydroxychloroquine. These include the SARS coronavirus. ${ }^{6}$ Studies with experimental animals have offered a variety of evidence about the human coronavirus $\mathrm{OC}_{4} 3^{6}$, enterovirus EVA71 ${ }^{7}$, Zika virus ${ }^{8}$ and influenza A H5N71. ${ }^{9}$ However, a 
randomized, double-blind placebo-controlled clinical study by Paton et al. ${ }^{10}$ provided evidence that chloroquine did not affect influenza virus infection. An in vitro study of the Chikungunya virus reported a promising antiviral activity. ${ }^{11}$ However, in vivo studies showed that chloroquine increased alpha virus replication due to immune modulation and anti-inflammatory properties. ${ }^{12}$ In addition to all of this, these two medications are used for treatment of autoimmune situations like systemic lupus erythematosus and rheumatoid arthritis. ${ }^{13}$ Hydroxychloroquine and chloroquine accumulate in lysosomes of phagocytic cells and auto phagosomes and change local $\mathrm{pH}$ concentrations and may inhibit important cellular functions and molecular pathways affecting immune activation (MHC class II expression inhibition, antigen presentation, reduction of $\mathrm{CD} 154$ by $\mathrm{T}$ cells, inhibition of production of a variety of proinflammatory cytokines like IL-2, IFN $\alpha$, and TNF protecting against cytokine-mediated cartilage absorption, effect on toll-like receptor 7 (TLR7) and TLR9 signal pathways, interaction with cAMP and cGMP activity). ${ }^{14}$ Chloroquine analogs are weak diprotic bases. They may infiltrate organelles like endosomes and lysosomes. This situation prevents endosome leak and viral fusion with the cell. This mechanism leads to consideration that these medications may be effective for treatment of COVID-19. Additionally, research has revealed that these medications intervene in SARS-CoV-2 receptor binding and glycosylation of ACE-2 receptors preventing subsequent infection. In vitro studies in recent times reported that chloroquine and hydroxychloroquine at MOI: 0.01 ratio had effective dose interval of $2.71 \mu \mathrm{M}$ and $4.51 \mu \mathrm{M}$ at $50 \%$ effective concentration for VEROE6 cells in SARS-CoV-2 infection. At all MOI (0.01,
0.02, 0.2 and 0.8), the EC50 for chloroquine is lower than for hydroxychloroquine. ${ }^{15}$ A study identified that hydroxychloroquine is more effective for SARS-CoV-2 infection compared to chloroquine. In this study, hydroxychloroquine sulfate was given twice on the first day at $400 \mathrm{mg}$ dose and then twice at $200 \mathrm{mg}$ dose for the following 4 days. ${ }^{16}$ In a double-blind, randomized phase IIb study in Brazil, high-dose chloroquine (600 mg twice per day for 10 days for 41 patient) and low-dose chloroquine (twice per day on the first day and once per day for the following 4 days in 40 patient) were administered in 81 patients carrying SARS-CoV-2 virus and admitted to hospital with severe acute respiratory distress syndrome. In these patients, the mortality rate was lower in the group given high-dose chloroquine compared to the low-dose group. The researchers have concluded that when oseltamivir and azithromycin are administered simultaneously, administration of high-dose chloroquine to COVID-19 patients is not recommended as it is not safe. In fact, age is an important factor. ${ }^{17}$

Chloroquine is a medication which is administered in oral form. For COVID-19 treatment, the recommended dose is $500 \mathrm{mg}$ tablet form given twice per day for 10 days. ${ }^{18}$ Bioavailability is close to complete with oral intake. Chloroquine is metabolized to the active metabolite of diacetyl chloroquine. This is mediated by CYP2C8 and CYP3A4. Chloroquine is the major substrate of CYP2D6. This enzyme comprises nearly $30 \%$ of inactivation. ${ }^{19}$ Chloroquine is eliminated in urine. Creatine clearance above $10 \mathrm{~mL} / \mathrm{min}$ does not require dose adjustment. The side effects of chloroquine and hydroxychloroquine are usually mild and temporary. The most commonly observed side effects are those linked to gastrointestinal 
intolerance. These include nausea, vomiting, abdominal cramps, and metallic taste in the mouth. Retinopathy may be observed with high-dose for a long period. Both chloroquine and hydroxychloroquine have minimal risk in pregnancy. These agents are accepted as safe. However, the limit between therapeutic and toxic doses is narrow and chloroquine intoxication may cause lifethreatening cardiovascular disorders. Though rare, people with heart disease and lengthened QTc should avoid use due to torsades de pointes. ${ }^{20}$ To minimize cardiac adverse effects, administration should be avoided with medications that lengthen QTc and CYP2D6 inhibitors. As a result, there should be definite rules for the use of these medications, and self-treatment is not recommended. ${ }^{21}$ This is important especially in elderly patients with heart disease receiving cardiotoxic medications. Phase IV studies reported hypoglycemia advancing to loss of consciousness when these medications were administered after antidiabetic medications in patients with diabetes. As a result, an important element is routine monitoring of patients receiving chloroquine treatment with blood sugar and electrocardiogram tests due to QTc interval and hypoglycemia. Due to reduced chelation potential and bioavailability, chloroquine administration should be avoided within 4 hours of antacid administration. There is an interaction between proton pump inhibitors (PPI) and chloroquine analogs. PPI may block $\mathrm{H}+$ and $\mathrm{K}+$ ATPase in lysosomes and elevate $\mathrm{pH}$ and reduce medication accumulation which may weaken immunomodulatory effects. However, the in vivo effects of this interaction are unknown. ${ }^{22}$ These medications need to be better researched with clinical studies of COVID-19 cases.

\section{Remdesivir}

Remdesivir (GS-5734) is a nucleotide analog preliminary medication metabolized in the cell to an adenosine triphosphate analog inhibiting viral RNA polymerases. Remdesivir has a broad-spectrum effect against members of many virus families including filoviruses and coronaviruses. In vivo and in vitro studies have shown prophylactic and therapeutic efficacy. ${ }^{23}$ In the deadly murine model of MERS, remdesivir was proven to be superior to combined interferon beta and lopinavir-ritonavir regime. ${ }^{24}$ Remdesivir is a strong inhibitor of SARS-CoV-2 replication in the epithelial cells of the human nose and bronchial airway. A study by Jonathan et al. administered remdesivir treatment of $200 \mathrm{mg}$ intravenous on the $1^{\text {st }}$ day and then $100 \mathrm{mg}$ for 9 days for patients admitted with COVID-19 diagnosis with disease due to SARS-CoV-2 infection. They identified $68 \%$ improvement. However, the researchers stated there was a need for randomized placebo-controlled studies to measure the efficacy of the medication. ${ }^{25}$ The potential mechanisms for remdesivir in COVID-19 are still uncertain. A variety of theories have been proposed in order to interpret the effect of remdesivir. The first of these is that though remdesivir does not disrupt exoribonuclease activity, it may affect nsp 12 polymerase. ${ }^{26}$ Additionally, remdesivir may effectively produce active nucleoside triphosphate (NTP) acting pharmacologically as an RNA chain terminator and alternative substrate. NTP active triphosphates are included in viral RNA inhibiting coronaviruses. There is a high genetic barrier for coronavirus to be able to develop resistance against remdesivir. ${ }^{27,28}$ This situation leads to the consideration that remdesivir may preserve its efficacy for coronavirus treatment without resistance. 
Experimental studies have observed that therapeutic remdesivir (administered 2 hours after infection) inhibited SARS-CoV-2 replication but did not show prophylactic effect in timed tests using Vero-6 cells. ${ }^{29}$ Clinical studies in the USA reported that a patient exposed to COVID-19 infection improved after remdesivir administration. ${ }^{30}$ Another clinical research identified $68 \%$ improvement in 53 patients with severe COVID-19. ${ }^{31}$ The evidence presented in experimental studies and clinical research lead to the conclusion that remdesivir may be effective for COVID-19 treatment. However, there are insufficient randomized, controlled studies to assess the efficacy and safety of remdesivir in COVID-19 cases. As a result, there is a need for more randomized and controlled studies to be performed. Hence, it appears that the benefit-harm ratio of remdesivir in COVID-19 treatment has still not been fully explained. Remdesivir was proven to inhibit coronavirus in in vivo and in vitro studies. It was identified to improve reduced respiratory functions due to coronavirus effects both prophylactically and therapeutically. However, it would be wrong to say anything definite in COVID-19 cases because there is an insufficient amount of evidence.

\section{Favipiravir}

Favipiravir

(T-705;

6-fluoro-3-hydroxy-2-

pyrazinecarboxamide) is a new antiviral compound selectively and strongly inhibiting RNA polymerase linked to RNA in influenza and many other RNA viruses. Favipiravir is phosphorybosylated to the active form of favipiravir-ribofuranocyl-5' triphosphate (RTP) by cellular enzymes. The antiviral effect occurs when viral RNA polymerase mistakenly identifies favipiravir-RTP as purine nucleotide and weakens with the addition of pu- rine nucleic acids. It was shown to inhibit all influenza A, $\mathrm{B}$, and $\mathrm{C}$ serotypes and strains. Additionally, both in vivo and in vitro models have shown an effect against a range of arene, bunya and flavivirus. Strong in vitro activity was shown against alphavirus, paramicrovirus and norovirus families. ${ }^{32}$

A study with healthy Japanese volunteers related to the pharmacokinetics of favipiravir showed that maximum plasma concentrations were reached 2 hours after oral administration and then reduced with a short half-life of 2-2.5 hours. Favipiravir had a 54\% binding rate to plasma proteins. The binding percentages for favipiravir to human serum albumin and $\alpha 1$-acid glycoprotein are $65 \%$ and $6.5 \%$, respectively. The main medication metabolism occurs in the liver mediated by aldehyde oxidase and partly by xanthine oxidase. The inactive oxidative metabolite of T-705-M1 is excreted by the kidneys. ${ }^{33}$

Dose selection is critical for antiviral purposes. The IC50 of favipiravir displays variations from nanomolar to micromolar concentrations in viral studies. Clinical research in Japan stated the permitted favipiravir regime for influenza was $3200 \mathrm{mg}$ oral loading dose on the $1^{\text {st }}$ day (1600 mg every 12 hours) and then $600 \mathrm{mg}$ on the $2^{\text {nd }}$ and $5^{\text {th }}$ days ${ }^{34}$. A higher dose regime $\left(1800 \mathrm{mg}\right.$ twice on $1^{\text {st }}$ day, then $800 \mathrm{mg}$ twice per day) is accepted in phase III. This regime has proven efficacy and safety for influenza. Adverse reactions include mild and moderate severity diarrhea, asymptomatic increase in blood uric acid and transaminases, and reduction in neutrophil count. ${ }^{35} \mathrm{~A}$ study in China used favipiravir for COVID-19 treatment and showed $3200 \mathrm{mg}$ on the $1^{\text {st }}$ day $(1600 \mathrm{mg}$ twice per day) as loading dose, then $1200 \mathrm{mg}$ maintenance dose on 
the $2^{\text {nd }}$ and $14^{\text {th }}$ days (600 mg twice per day) was effective. $^{36}$

When investigated from a pharmacokinetic aspect, in vitro studies of favipiravir showed it was potent on selective estrogen receptor blockers, $\mathrm{H} 2$ receptor antagonists, cimetidine calcium channel blockers, the antiarrhythmic medication of propafenone and tricyclic antidepressant amitriptyline AO receptors. ${ }^{37}$ Though there is no clinical information based on AO inhibition, obvious DDI was reported between cimetidine and zaleplon. ${ }^{38}$ Interactions between these medications and favipiravir should be carefully monitored. ${ }^{33}$

The use of favipiravir may be mentioned for COVID-19. However, there is still a need for more clinical research in order to interpret the definite efficacy of favipiravir. Potential interactions linked to AO inhibition should not be ignored.

\section{Lopinavir-Ritonavir}

Lopinavir-ritonavir were previously known as protease inhibitors intervening in the replication and synthesis of the HIV causing the production of non-infectious virus particles. As a result of the molecular model assessment, lopinavir and ritonavir were reported to be able to bind to the endopeptidase $\mathrm{C} 30$ in the SARS-CoV-2 protease. This situation led to the consideration that lopinavir and ritonavir may show antiviral effects by inhibiting SARSCoV-2 protein synthesis. Additionally, there is evidence that the use of lopinavir/ritonavir (LPV/RTV) alone or in combination with other antiviral medications improves severe ARDS developing linked to SARS and MERS..$^{39,40}$ It was considered that LPV/RTV may be effective in treatment of COVID-19 infection considering the similar- ity of SARS-CoV-2 to this virus. ${ }^{41}$ Lopinavir is a sensitive substrate for cytochrome P540 3A4 (CYP3A4) and p-glycoprotein and binds to protein in plasma at high rates (98-99\%). Absorption occurs at stomach $\mathrm{pH}$ linked to intestinal CYP3A4 expression and P-glycoprotein activity. Hepatic and intestinal CYP3A4 expression contributes to systemic clearance of lopinavir. Ritonavir binds to protein at high rates. It is a substrate of CYP3A4 and to a lesser extent CYP2D6 and P-glycoprotein. ${ }^{42}$ Clinical drug-drug interaction studies have shown that LPV/RTV inhibits CYP3A4 and CYP2D6, and induces CYP2C9, CYP2C19 and CYP1A2. ${ }^{43}$ LPV/RTV has shown potential to both inhibit and induce UDP glucuronyl transferase. When administered together, LPV/RTV was shown to have drug interactions mediated by drugmetabolizing enzymes, in addition to drug-carrier mediated interactions. As an example, when LPV/RTV are administered together, plasma rosuvastatin and pravastatin concentrations contain solute carrier organic anion transporter 1B1 (SLCO1B1) and ATP-binding cassette subfamily G member 2 (ABCG2)/ Breast cancer resistance protein (BCRP) carriers. ${ }^{44,45}$. As a result, it is necessary to be careful of drug-drug interactions when using LPV/RTV for SARS-CoV-2 infections.

\section{Nitazoxanide}

Nitazoxanide and the active metabolite tizoxanide were shown to have strong in vitro activity against SARSCoV-2 and MERS-CoV in Vero E6 cells. Nitazoxanide increases cytoplasmic RNA perception and type I IFN pathways regulating natural antiviral mechanisms. Due to broad-spectrum antiviral activity, it was trialed in randomized controlled clinical studies for treatment of influenza and other acute respiratory tracts. However, results 
have still not gained certainty in terms of clinical use. ${ }^{13}$ Nitazoxanide is suitable for intake with food. In plasma, tizoxanide binds to proteins at $99 \%$ rates. Nitazoxanide was not studied in patients with renal and liver failure. As a result, no recommendations are known about dose setting. There is no data available for geriatric and pediatric groups. Adverse effects of abdominal pain, nausea and headache are most common. Apart from this, patients may have color changes in eyes and urine, diarrhea, dizziness, skin rash, and gastroesophageal reflux. ${ }^{46,19}$ Nitazoxanide is not metabolized by CYP540 enzymes. As a result, interaction with other drugs does not occur by this route. As nitazoxanide binds to proteins at high rates, interaction with other drugs may be in the form of competition for binding sites with other drugs binding to proteins at high rates. ${ }^{19}$

\section{Nelfinavir}

Nelfinavir mesylate was developed as an anti-human immunodeficiency virus (HIV) protease inhibitor. Apart from this, cell culture studies have reported nelfinavir inhibits SARS replication and cytopathic effects. In addition to strong activity against HIV protease, it was observed to have multiple effects on cellular processes including apoptosis and necrosis and inducing cellprotective mechanisms. ${ }^{47}$ During the SARS epidemic emerging in 2002, nelfinavir was identified as a potential agent with activity against SARS-CoV infection. Effects against SARS-CoV-2 and SARS-CoV were not researched in humans. The recommended dose for HIV treatment is $750 \mathrm{mg} 3$ times per day by the oral route or $1250 \mathrm{mg}$ twice per day. ${ }^{19}$ Nelfinavir is metabolized by CYP3A4 and CYP2A19. As a result, it may interact with drugs metabolized by these enzymes. Nelfinavir may cause gastrointestinal intolerance. $^{48}$

\section{Oseltamivir}

Neuraminidase inhibitors are expected to reduce influenza complications in people at high risk in terms of influenza complications. Additionally, one of the most unsettling aspects of oseltamivir use is severe sudden death, and oseltamivir is reported to have severe neuropsychiatric adverse reactions including neuropsychiatric behavior causing accidental death. Since 2007 in Japan, it is contraindicated in children from 10-19 years due to risk of abnormal behavior. ${ }^{49}$ Studies about oseltamivir for COVID-19 treatment continue. However, a study in Wuhan city reported that no positive outcomes were observed after antiviral treatment administered with oseltamivir. ${ }^{50}$ Oseltamivir, favipiravir and chloroquine are used in a variety of combinations. Some clinical research has added oseltamivir. However, a review by Sander et al. reported that oseltamivir has no benefit for COVID-19 treatment after influenza is excluded. ${ }^{51}$

\section{Tocilizumab}

Tocilizumab is an FDA-approved monoclonal antibody for chimeric antigen receptor $\mathrm{T}$ cell-derived cytokine release syndrome, giant cell arteritis, rheumatoid arthritis, and polyarticular and juvenile idiopathic arthritis. ${ }^{19}$ Data show that lung damage develops linked to inflammatory cytokine fluctuations in COVID-19 patients and, as a result, a cytokine storm forms. As a result of viral replication, hyperinflammation and further lung damage, the immune system is activated to release a variety of signal proteins like IL. IL-6 is an important inflammatory protein on this pathway. Tocilizumab binding to IL-6 recep- 
tors blunts the cell signal and effectively downregulates the excessive immune response. In patients infected with SARS virus, cytokine release syndrome (CRS) was identified as a result of the release of proinflammatory markers containing IL- 6 and TNF $\alpha$. In MERS patients, IL-6, IL-8 and IL $1 \beta$ elevations were discovered. ${ }^{52}$ In severe COVID-19 patients in Wuhan city, high cytokine levels were recorded including IL-6 and granulocyte stimulating factors. ${ }^{53}$ Data recorded in Wuhan stated that in severe COVID-19 patients, tocilizumab added to lopinavir, methylprednisolone, and oxygen treatment caused rapid falls in fever, $75 \%$ rate of improvement in oxygenation and $95 \%$ of patients were discharged from hospital. ${ }^{54}$

For many indications, the dose of tocilizumab is 800 $\mathrm{mg} / \mathrm{kg}$. The dose for use in COVID-19 treatment still remains uncertain. Additionally, a study used a dose of $400 \mathrm{mg} / \mathrm{kg}^{54}$

Tocilizumab should be carefully assessed in terms of adverse effects. Patients should be assessed for active or latent tuberculosis before administering tocilizumab. After tocilizumab use, gastrointestinal perforation was reported in patients with diverticulitis history or receiving high-dose corticosteroids. ${ }^{19}$

There may be drug-drug interactions with tocilizumab linked to increased CYP540 activity. In vivo studies reported that tocilizumab may enter interaction with simvastatin linked to increased CYP3A4 activity. Similarly, it may enter interaction with omeprazole linked to CYP19 activity. ${ }^{19}$

\section{Plasma Treatment}

The treatment method based on human plasma from people who have healthily recovered from coronavirus disease involves the transfer of passive immunity with the aim of restoring the immune system, suppressing viremia, and neutralizing the virus in the critical disease period. Retrospective research with 40 participants administered human plasma from recovered patients after failure of treatment with 3-day methylprednisolone and ribavirin. Of these patients, $74 \%$ were discharged in 22 days. ${ }^{19,} 55$ The same study discharged only $19 \%$ of patients receiving high-dose corticosteroids. For the use of recovered human plasma to be effective, it is necessary to administer this treatment in the early periods of the disease. In fact, it was reported that SARS and viremia reached a peak in the first week. Recovered human plasma treatment is still in the experimental stage. However, it may positively affect treatment progression. However, clinical research related to this continues. Patients who volunteer to participate in these types of clinical research will help to determine the efficacy of this form of treatment.

\section{Corticosteroids}

The purpose of corticosteroid use in COVID-19 patients is to reduce the inflammatory response causing acute lung damage and acute respiratory distress syndrome. This benefit may severely suppress delayed viral clearance and increase secondary infection risk. Observational studies in SARS and MERS patients did not offer any findings related to improved survival. ${ }^{51}$ However, it may be associated with delayed viral clearance in respiratory tract and blood and high rates of complications like hyperglycemia, avascular necrosis and psychosis. ${ }^{56}$ Additionally, a meta-analysis of 10 observational studies including 6548 patients showed that corticosteroids increased mortality risk and had 2 times higher secondary infection risk. ${ }^{57}$ Another retrospective study found no benefit from 300 
mg hydrocortisone per day in critical MERS patients for 90-day mortality; however, they found viral clearance was delayed in these patients. ${ }^{56} \mathrm{~A}$ study in recent times administered corticosteroids to 11 of 31 COVID-19 patients. Regression analysis found no correlation between corticosteroid intake with virus clearance duration and hospital stay. However, an interesting finding is that 2 patients with hepatitis $B$ infection had slower virus clearance duration in this study. ${ }^{58}$ In this situation, corticosteroids may be considered if required for alternative indications like only septic shock or bronchoconstriction. They should be avoided in routine use.

\section{Azithromycin}

Azithromycin was shown to be an active agent in vitro against the Ebola virus. Apart from this, azithromycin has good potential to prevent severe respiratory tract infections in preschool children. ${ }^{59}$ It is administered to patients affected by viral infections. According to a study, $500 \mathrm{mg}$ on the $1^{\text {st }}$ day and $250 \mathrm{mg}$ azithromycin on days 2-5 significantly strengthened the efficacy of hydroxychloroquine. ${ }^{60}$ However, a study by Borba et al. ${ }^{17}$ administered high dose and low dose chloroquine to 81 adult patients. They observed the death rate with highdose chloroquine was reduced by $50 \%$. However, the researchers did not recommend high-dose chloroquine administered simultaneously to oseltamivir and azithromycin especially due to safety dangers. There are no other clinical studies related to the use of azithromycin for COVID-19. The reason for the very few studies showing viral efficacy of azithromycin is that it is a classic antibiotic and has unknown effects on SARS-CoV-2 infection.

\section{Vaccinations}

The whole world is united in facing the COVID-19 pandemic. In this war, health workers and researchers around the world are struggling against the SARS-CoV-2 threat. Researchers are performing record levels of studies to find a vaccine against this virus.

Approaches to vaccine development include classic inactivated and weakened vaccines, protein subunit and virus-like particle vaccines, viral vector-based vaccines, and DNA- and RNA-based vaccines. Each approach has its own specific advantages and disadvantages. However, all approaches should be developed at the same time in order to find an effective vaccine. ${ }^{61,62}$

Among structured proteins on the virus, the spike protein is the most promising for vaccine development. This vaccine development is common for all coronaviruses and ensures the formation of an immune response by exposing an individual's immune system and recalling this response for protection in the future. Additionally, this vaccination should prevent entry of the virus into susceptible cells and prevent infection. ${ }^{63}$

As of December 11, 2020, fifty-eight vaccine candidates are currently conducting the clinical trial phase. Forty of these are at Phase I-II and 18 of them are at Phase IIIIV. ${ }^{64}$ No vaccine candidates have yet completed Phase III. Prominent of these vaccines include Pfizer-BioNTech (MRna), Moderna (MRna), CanSino (Adenovirüs), Gamaleya (Adenovirüs), Johnson\&Johnson (Adenovirüs), Oxford-AstraZeneca (Adenovirüs), Novovax (Protein), Vektör Enstitüsü (Protein), Sinopharm-Pekin (Inaktive), Sinopharm-Wuhan 
(Inaktive), Sinovac (Inaktive). ${ }^{65}$ It is to be hoped that all studies will achieve success in the shortest time.

\section{CONCLUSION}

The COVID-19 pandemic is a very large global pandemic. The world was unprepared for this pandemic which required acceleration of pharmaceutical industry studies and research to develop new treatments targeting SARSCoV-2 infection. This process may be beneficial for COVID-19 patients and scientists working in all areas of medical science continue to attempt a variety of treatments in the name of struggling with this virus. Though this review may be encouraging in terms of treatment with some agents, the side effects linked to the use of medications beneficial for treatment may be severe and evidence is still not definite. The evidence related to COVID-19 treatment is changing nearly every day. However, there is a need for more information about medications used or that can be used for COVID-19 treatment. Knowing the pharmacodynamic and pharmacokinetic properties of medications will lead to smarter structuring of treatment. The treatment process should be individualized according to the patient and disease progression.

At the moment, there is no vaccine and/or treatment strategies available for full treatment or protection from SARS-CoV-2. Additionally, it does not appear possible to finalize these within 3-12 months. As a result, public health strategies effective against this continuing pandemic are required. Among these strategies are early case identification and isolation, contact tracing of potential secondary cases, limitation of close contact, travel limitations, social isolation, hygiene and regular handwashing. If the required conditions are met, the virus reproduction count will drop and transmission rate will reduce. These precautions are temporary to gain time while vaccine and medication development studies continue.

\section{REFERENCES}

1. Park SE. Epidemiology, virology, and clinical features of severe acute respiratory syndrome -coronavirus-2 (SARSCoV-2; Coronavirus Disease-19). Clin Exp Pediatr. 2020;63(4):119-124.

2. Kim KH. COVID-19. Int Neurourol J. 2020;24(1):1-1.

3. Esposito S, Noviello S, Pagliano P. Update on treatment of COVID-19: ongoing studies between promising and disappointing results. Infez Med. 2020;28(2):198-201.

4. Aguiar ACC, Murce E, Cortopassi WA, et al. Chloroquine analogs as antimalarial candidates with potent in vitro and in vivo activity. Int $\mathbf{J}$ Parasitol Drugs Drug Resist. 2018;8(3):459-464.

5. Inglot AD. Comparison of the antiviral activity in vitro of some non-steroidal anti-inflammatory drugs. J. Gen. Virol. 1969;4(2):203-214.

6. Keyaerts E, Li S, Vijgen L, Verbeeck J, Van Ranst M, Maes $\mathrm{P}$. Antiviral activity of chloroquine against human coronavirus OC43 infection in newborn mice. Antimicrob Agents Chemother. 2009;53(8):3416-3421.

7. Tan YW, Yam WK, Sun J, Chu JJI. An evaluation of chloroquine as a broad-acting antiviral against hand, foot and mouth disease. Antivir Res. 2018;149(2018):143-149.

8. Li C, Zhu X, Ji X, et al. Chloroquine, a FDA-approved drug, prevents Zika virus infection and its associated congenital microcephaly in mice. EBioMedicine. 2017;24:189-194.

9. Yan Y, Zou Z, Sun Y, et al. Anti-malaria drug chloroquine is highly effective in treating avian influenza A H5N1 virus infection in an animal model. Cell Res. 2013;23(2):300-302.

10. Paton NI, Lee L, Xu Y, et al. Chloroquine for influenza prevention: a randomised, double-blind, placebo controlled trial. Lancet Infect. Dis 2011;11(9):677-683.

11. Delogu I, de Lamballerie $X$. Chikungunya disease and chloroquine treatment. J Med Virol. 2011;83(6): 1058-1059.

12. Katz SJ, Russell AS. Re-evaluation of antimalarials in treating rheumatic diseases: re-appreciation and insights into new mechanisms of action. Curr Opin Rheumatol. 2011;23(3):278-281.

13. Şimşek Yavuz S, Ünal S. Antiviral Treatment of COVID19. Turk J Med Sci. 2020;50:611-619.

14. Schrezenmeie T, Dörner E. Mechanisms of action of hydroxychloroquine and chloroquine: implications for rheumatology. Nat. Rev. Rheumatol. 2020;16:155-166.

15. Lu YL, Chen CC, Chang MY. Potential therapeutic agents against COVID-19: What we know so far. J Chin Med Assoc. 2020;83(6):534-536.

16. Yao X, Ye F, Zhang M, et al. In vitro antiviral activity and projection of optimized dosing design of hydroxychloroquine for the treatment of severe acute respiratory syndrome coronavirus 2 (SARS-CoV-2). Clin Infect Dis. 2020;71(15):732-739.

17. Borba MGS, Val FFA, Sampaio VS, et al. Effect of High vs Low Doses of Chloroquine Diphosphate as Adjunctive Therapy for Patients Hospitalized With Severe Acute Respiratory Syndrome Coronavirus 2 (SARS-CoV-2) Infection: A Randomized Clinical Trial. JAMA Netw Open. 2020;3(4):e208857.

18. Jie Z, He H, Xi H, Zhi Z. Multicenter collaboration group of Department of Science and Technology of Guangdong Province and Health Commission of Guangdong Province for chloroquine in the treatment of novel coronavirus pneumonia. Expert consensus on chloroquine phosphate for the treatment of novel coronavirus pneumonia. 2020;43(3):185-188. 
19. Barlow A, Landolf KM, Barlow B, et al. Review of Emerging Pharmacotherapy for the Treatment of Coronavirus Disease 2019. Pharmacotherapy. 2020; 40(5):416-437.

20. Plaquenil Hydroxychloroquine Sulfate Tablets, USP. https://www.accessdata.fda.gov/drugsatfda_docs/label/2 017/009768s037s045s047lbl.pdf. Access Date: 28.02.2021

21. Touret F, de Lamballerie X. Of chloroquine and COVID19. Antiviral Res. 2020;177:104762.

22. Aralen. Chloroquine Phosphate, USP. https://www. access datafda.gov/drugsatfda_docs/label/2017/00600 2s044lbl.pdf. Access Date: 28.02.2021.

23. de Wit E, Feldmann F, Cronin J, et al. Prophylactic and therapeutic remdesivir (GS-5734) treatment in the rhesus macaque model of MERS-CoV infection. Proc Natl Acad Sci. 2020;117(12):6771-6776

24. Sheahan TP, Sims AC, Leist SR. Comparative therapeutic efficacy of remdesivir and combination lopinavir, ritonavir, and interferon beta against MERS-CoV. Nat Commun. 2020;11(1):222. doi: 10.1038/s41467-01913940-6.

25. Grein J, Ohmagari N, Shin D, et al. Compassionate Use of Remdesivir for Patients With Severe Covid-19. N Engl J Med. 2020;382(24):2327-2336.

26. Agostini ML, Andres EL, Sims AC, et al. Coronavirus susceptibility to the antiviral remdesivir (GS-5734) is mediated by the viral polymerase and the proofreading exoribonuclease. Asm Journals. 2018;9(2):e00221-18.

27. Li Z, Wang X, Cao D, Sun R, Li C, Li G. Rapid Review for the Anti-Coronavirus Effect of Remdesivir. Drug Discov Ther. 2020;14(2):73-76.

28. Warren TK, Jordan R, Lo MK, et al. Therapeutic efficacy of the small molecule GS-5734 against Ebola virus in rhesus monkeys. Nature. 2016;531(7594):381-385.

29. Wang $\mathrm{M}$, Cao $\mathrm{R}$, Zhang $\mathrm{L}$, et al. Remdesivir and chloroquine effectively inhibit the recently emerged novel coronavirus (2019-nCoV) in vitro. Cell Res. 2020;30(3):269-271.

30. Holshue ML, DeBolt C, Lindquist S, et al. First case of 2019 novel coronavirus in the United States. N Engl J Med. 2020;382(10):929-936.

31. Grein J, Ohmagari N, Shin D, et al. Compassionate use of remdesivir for patients with severe Covid 19. N Engl J Med. 2020;382(24):2327-2336.

32. Furuta Y, Gowen BB, Takahashi K, Shiraki G, Smee BF, Barnard DL. Favipiravir (T-705), a Novel Viral RNA Polymerase Inhibitor. Antiviral Res. 2013;100(2):446454.

33. Du YX, Chen XP. Favipiravir: Pharmacokinetics and Concerns About Clinical Trials for 2019-nCoV Infection. Clin Pharmacol Ther. 2020;108(2):242-247.

34. Wang Y, Guohui F, Salam A, et al. Comparative effectiveness of combined favipiravir and oseltamivir therapy versus oseltamivir monotherapy in critically ill patients with influenza virus infection. $\mathbf{J}$ Infect Dis. 2020;323(11):1061-1069.

35. Madelain, V, Nguyen THT, Olivo A, et al. Ebola virus infection: review of the pharmacokinetic and pharmacodynamic properties of drugs considered for testing in human efficacy trials. Clin Pharmacokinet. 2016;55:907-923.

36. Cai, Q, Yang M, Liu D, et al. Experimental treatment with Favipiravir for COVID-19: an open-label control study. Engineering. 2020;6(10):1192-1198.

37. Obach RS, Huynh P, Allen MC, Beedham C. Human liver aldehyde oxidase: inhibition by 239 drugs. J Clin Pharmacol. 2004;44(1):7-19.

38. Renwick AB, Ball SE, Tredger JM, et al. Inhibition of zaleplon metabolism by cimetidine in the human liver: in vitro studies with subcellular fractions and precision-cut liver slices. Xenobiotica. 2002;32(10):849-862.

39. Sheahan TP, Sims AC, Leist SR, et al. Comparative therapeutic efficacy of remdesivir and combination lopinavir, ritonavir, and interferon beta against MERSCoV. Nat Commun. 2020;11(1):222.
40. Zumla A, Chan JF, Azhar EI, Hui DSC, Yuen YK. Coronaviruses - drug discovery and therapeutic options. Nat Rev Drug Discov. 2016;15(5):327-347.

41. Li H, Liu SM, Yu XH, Tang SL, Tang CK. Coronavirus disease 2019 (COVID-19): current status and future perspectives. Int J Antimicrob Agents. 2020;55(5):105951.

42. van der Laan LE, Garcia-Prats AJ, Schaaf HS, Tikiso T, Wiesner L. Pharmacokinetics and Drug-Drug Interactions of Lopinavir-Ritonavir Administered with Firstand Second-Line Antituberculosis Drugs in HIVInfected Children Treated for Multidrug-Resistant Tuberculosis. Antimicrob Agents Chemother. 2018;62(2):e00420-17.

43. Foisy MM, Yakiwchuk EM, Hughes CA. Induction effects of ritonavir: implications for drug interactions. Ann Pharmacother 2008;42(7):1048-1059.

44. Mary B. Wire, Heidi B. McLean, Pendry C, Theodore D, Park JW, Peng B. Assessment of the Pharmacokinetic Interaction between Eltrombopag and Lopinavir-Ritonavir in Healthy Adult Subjects. Antimicrob Agents Chemother. 2012;56(6):2846-2851.

45. Kiser JJ, Gerber JG, Predhomme JA, Wolfe P, Flynn DM, Hoody DW. Drug/Drug interaction between lopinavir/ritonavir and rosuvastatin in healthy volunteers. J. Acquir. Immune Syndr. 2008;47(5):570-578.

46. Gamiño-Arroyo AE, Guerrero ML, McCarthy S, et al. Efficacy and safety of nitazoxanide in addition to standard of care for the treatment of severe acute respiratory illness. Clin Infect Dis. 2019;69(11):1903-1911.

47. Musarrat F, Chouljenko V, Dahal A, et al. The anti-HIV Drug Nelfinavir Mesylate (Viracept) Is a Potent Inhibitor of Cell Fusion Caused by the SARSCoV-2 Spike (S) Glycoprotein Warranting Further Evaluation as an Antiviral Against COVID-19 Infections. J Med Virol. 2020;92(10):2087-2095.

48. Viracept. https://www.accessdata.fda.gov/drugsatfda docs/label/2005/021503s006lbl.pdf. Access Date: 28.02.2021.

49. Hama R. The mechanisms of delayed onset type adverse reactions to oseltamivir. Infect Dis. 2016;48(9):651-660.

50. Wang $\mathrm{D}, \mathrm{Hu} \mathrm{B}, \mathrm{Hu} \mathrm{C}$, et al. Clinical characteristics of 138 hospitalized patients with 2019 novel coronavirusinfected pneumonia in Wuhan, China. JAMA. 2020;323(11):1061-1069.

51. Sanders JM, Monogue ML, Jodlowski TZ, Cutrell JB. Pharmacologic Treatments for Coronavirus Disease 2019 (COVID-19): A Review. JAMA. 2020;323(18):18241836.

52. Cameron MJ, Bermejo-Martin JF, Danesh A, Muller MP, Celvin DJ. Human immunopathogenesis of severe acute respiratory syndrome (SARS). Virus Res. 2008;133(1):13-19.

53. Chen N, Zhou M, Dong X, et al. Epidemiological and clinical characteristics of 99 cases of 2019 novel coronavirus pneumonia in Wuhan, China: a descriptive study. Lancet. 2020;395(10223):507-513.

54. Xu X, Han M, Li T, et al. Effective treatment of severe COVID-19 patients with Tocilizumab. Proc Natl Acad Sci USA. 2020;117(20):10970-10975.

55. Soo YOY, Cheng Y, Wong R, et al. Retrospective comparison of convalescent plasma with continuing high-dose methylprednisolone treatment in SARS patients. Clin Microbiol Infect. 2004;10(7):676-678.

56. Arabi YM, Mandourah Y, Al-Hameed F, et al. Corticosteroid therapy for critically ill patients with Middle East respiratory syndrome. Am J Respir Crit Care Med. 2018;197(6):757-767.

57. Ni YN, Chen G, Sun J, Liang BM, Liang ZA. The effect of corticosteroids on mortality of patients with influenza pneumonia: a systematic review and meta-analysis. Crit Care. 2019;23(1):99 doi:10.1186/s13054-019-2395-8.

58. Zha L, Li S, Pan L, et al. Corticosteroid Treatment of Patients With Coronavirus Disease 2019 (COVID-19). Med J Aust. 2020;212(9):416-420. 
59. Jean SS, Lee PI, Hsueh PR. Treatment Options for COVID-19: The Reality and Challenges. J Microbiol Immunol Infect. 2020;53(3):436-443.

60. Gautret P, Lagier J, Parola P, et al. Hydroxychloroquine and azithromycin as a treatment of COVID-19: results of an open-label non-randomized clinical trial. Int $\mathbf{J}$ Antimicrob Agents. 2020;56(1):105949.

61. Uddin M, Mustafa F, Rizvi TA, et al. SARS-CoV2/COVID-19: Viral Genomics, Epidemiology, Vaccines, and Therapeutic Interventions. Viruses. 2020;12(5):526.

62. Amanat F, Krammer F. SARS-CoV-2 Vaccines: Status Report. Immunity 2020;52(4):583-589.

63. Shang W, Yang Y, Rao Y, Rao X. The outbreak of SARS-CoV-2 pneumonia calls for viral vaccines. NPJ Vaccines. 2020;5(18):1-3.

64. Coronavirus disase (COVID-19): Vaccines. https:// www.who.int /news-room/q-a-detail/ coronavirus disease-(covid-19)-vaccines?adgroupsurvey $=\{$ ad groupsurvey \& \&gclid=EAIaIQobChMI87j0sJWN7wIVR QWiAx1dYQJxEAAYASAAEgJX7vD_BwE. Access Date: 19.02 .2021

65. WHO Coronavirus Disase (COVID-19) Dashboard. https://covid19.who.int/?gclid=EAIaIQobChMIyouL66u N7wIVSIXVCh1-YwuIEAAYASAAEgImBfD_BwE. Access Date: 28.02.2021 